\title{
Is the Face-to-Face Conference Still Essential?
}

\section{Karen Munro and Merinda McLure}

Karen Munro is Head of the University of Oregon Portland Library \& Learning Commons. Merinda McLure is Health and Human Sciences Librarian at Colorado State University.

Correspondence concerning this column should be addressed to Karen Antell, Special Projects Librarian, and Molly Strothmann, Social \& Behavioral Sciences Librarian, University of Oklahoma Libraries, 401 W. Brooks St., Norman, OK 73019; email: kantell@ou.edu and mstrothmann@ou.edu.
Face-to-face conferences entail hundreds or thousands of flights and use up many other environmental, organizational, financial, and personal resources. Some librarians have argued for phasing them out in favor of virtual conferences, while others have said that in-person conferences still provide valuable opportunities that cannot be replicated online. In this final installment of "Taking Issues," our authors consider the question, "Can 'green librarians' justify the face-to-face library conference?"-Editors

\section{McLure:}

It seems like we've been rooming together at ALA conferences nearly every year since we graduated from The University of British Columbia's MLIS program in 2002 (yikes!). I remember that back then-when we were 'green librarians' in the other sense-we were both very interested in getting involved in professional service beyond our places of employment. We also held faculty status and academic librarian positions that exerted a certain amount of cultural pressure to both serve and conference. Those expectations naturally took us to ALA conferences, where we could befriend other librarians, keep learning, and become engaged with our profession nationally. I really feel that I've been amply rewarded on all those counts over the years.

Until only recently, that kind of service and professional involvement typically demanded a commitment to attending conferences in person. As technological developments have increasingly facilitated virtual conferences, we've acclimated to meeting and working virtually, and opportunities for professional service that don't require in-person conference attendance have expanded. I wonder how those developments have changed new librarians' experiences. Our early years in the profession featured regular conference attendance that really fostered my sense of a larger community of librarians and libraries. Has the next cohort of librarians lost something worthwhile by increasingly replacing that experience with a virtual substitute?

\section{Munro:}

Right, we came of age (professionally speaking) in the early 2000s, in a slightly different era of conference attendance and communication technology. It's amazing to reflect now, in 2014, and realize how much has changed in twelve years. ACRL started offering its virtual conference in 2005, with its platform getting more robust every year since then. ${ }^{1}$ Their elearning offerings have grown by leaps and bounds. When we 


\section{TAKING ISSUES}

started out, I remember that serving on an ACRL committee automatically meant committing to attend both the Annual conference and the Midwinter meeting, usually for two years. Now, more and more ACRL section committees_including the Instruction Section, on which we both served for several years-have reconsidered their requirements for in-person meetings. Without that built-in professional reason to attend, the 2014 Annual conference was probably the last one that you and I will both attend in person. We'll both continue to work with the section, but we no longer have an automatic reason to see each other once or twice a year! This makes me very sad, which says something about the importance of face-to-face conference attendance.

But since I'm arguing the opposite side of the question, I want to focus on how much has changed in twelve years. If we've come this far this fast-from a commitment to attend two in-person meetings a year, to no in-person commitment at all for most members- then where do we think we'll be in another ten or twelve years?

We're both academic librarians, so we have a limited view of this topic. We should really be talking with ALA staff and other folks like vendors and public librarians, who make up significant chunks of the audience for a conference like ALA and I'm sure have great insights into attendance trends. But I'm going to jump in and be iconoclastic anyway, and say that in another ten to twelve years, we'll see our largest national conference, ALA Annual, scaled back to about half or a quarter of its current in-person attendance.

I think there are three reasons for that: cost, the evolution of technology, and our own changing professional needs and perceptions.

I predict that the costs of travel are going to rise, the technology is going to evolve until we have better options for doing our work virtually, and our expectations of what we need to do at a conference (listen to lectures, do hands-on training, get certifications, etc.) are going to change. Taken together, those changes will make the traditional face-to-face conference less essential.

\section{McLure:}

You are a bold futurist! I love your optimism here and I certainly agree that the technologies that allow us to work or conference together from geographically remote locations seem to hold still more promise than we've already enjoyed. I've attended a few virtual conferences myself in recent years and have found them to be a fine forum for the largely lectureformat presentations that seem to continue to predominate at many conferences.

I'm really awed that technology makes it possible for me to attend events that would otherwise be inaccessible to me due to cost or geographical distance. I think I would have found this greater ease of access especially amazing as an early-career professional, when my income was lower and it was harder to prioritize personal funds for professional development, and when I was even more interested in exploring a wide variety of professional concentrations and concerns, before my job responsibilities began to suggest a narrower focus.

Your point that our expectations of conferences are likely to change reminds me of how online education is concurrently evolving, and of the likelihood that our changing capabilities and pedagogical knowledge might influence what learning or networking outcomes we'll expect from conferences in the future. Another prospect is that "the conference" may come to be something disseminated throughout our regular work lives. Maybe we'll come to think more and more in terms of individual sessions that we consume piecemeal instead of mass face-to-face gatherings. They might be offered under the auspices of a familiar "conference," but without a physical meeting, might our focus shift from the larger umbrella event to the individual component parts?

All that said-I admit, it's a struggle to stick to my side of the argument!-I do think there are affective aspects of the face-to-face experience that justify the in-person conference. I'm not sure how, without face-to-face conferences, I would have found some of the formative librarian friendships and connections that have influenced and educated me, brought me new opportunities, buoyed my morale through rough patches, and broadened my perspectives. In my virtual conference experiences to date, chat has served as the primary medium for communication, and it still feels like a very limited mode of interpersonal interaction. And you can't bring me chocolate from Portland, nor can we share a meal in a new city, via chat.

The face-to-face experience still feels richer, more immersive, and more participatory to me. I'd also estimate that more than half of the insights and ideas that I bring home from conferences come from unscheduled and informal interactions, rather than formal conference session content. I am finding recently that Tweets can add significantly to a conference experience, either face-to-face or virtual, but there is no virtual substitute yet for the real thing.

And I love the opportunity for post-event absorption and reflection that time physically away at conference and traveling home permits. I haven't yet succeeded in carving out that time for myself when I attend virtual conferences. Sometimes I even fail to protect the time required to attend, as deadlines rain down, and too often I'm quickly pulled back into pressing tasks and file my notes for a later day.

\section{Munro:}

I agree, in-person conference attendance is pretty powerful. There's a reason that we don't all sit at home all day and do our work over phone and email. Strictly speaking, we could probably do a lot of it that way-I happen to work at a remote location from my university's home campus, and I do a lot of my work with colleagues over videoconference, phone, and email. But there's nothing like taking a day to go and visit in person. Sometimes those days aren't as productive, on paper, as the days when I sit at my desk and plow through budget reports or lesson plans. But they're wonderfully productive 
in other ways-in building relationships, getting to know people, understanding complex issues, and so on. Likewise, your point about building in time to reflect on the conference experience is very well made. I agree-we need that time just as much as we need the iron-clad scheduling commitment of a plane ticket and a paid registration, to make sure we actually do the thing we signed up for. It's very hard to build in that kind of validation for ourselves without the larger structure of the conference to back it up.

So those are good points about the personal, affective value of face-to-face attendance. And I'm honestly not sure what virtual attendance has to offer yet, in that arena. It's still a weak point to me, one that we haven't figured out how to fully address. The affective quality may just be one of the downsides of virtual attendance. However, the traditional face-to-face conference has its inherent weak points, toothe cost, the environmental impact, the time commitment for hundreds or thousands of librarians (not just attendance, but travel days as well) — to say nothing of unheated hotels in Boston winters and the routine misery of flight delays. We shouldn't demand perfection from virtual conferences in order to consider them adequate alternatives, because we've never had perfection with our traditional approach.

Anyway, some of those problems seem likely to improve with better technology. The Oculus Rift, for instance, seems like science fiction at the moment, but it's getting closer and closer to market-ready. When we have a virtual reality device that can make you feel like you're really sitting in a room with a hundred other people-without giving you vertigo or motion sickness, without data loss or lag or problems with simultaneous inputs-then I think we're going to be playing a whole new game. When that's affordable, why not invest in a few of those devices and "send" your staff to conferences without flying them anywhere? Looking even farther ahead, I can imagine we'll have personal virtual reality devices just like we now have personal mobile phones. I use my own devices and accounts for work all the time, because there's no appreciable cost to me to do so, and it wouldn't make sense for the organization to carry those accounts and devices for me. I can imagine we're going to get to a place where virtual reality will happen on personal mobile devices... and once we get there, the question of face-to-face conferencing will be upended completely.

No, there's no guarantee that we're going to get exactly this solution, but it seems like one that's perched on the horizon right now. And it seems like a real game-changer for the whole world of business travel.

Of course, that leaves open questions about equity of access (How much will these magical devices cost?) and institutional policy (How will we decide how to deploy these kinds of technologies in the workplace?) and other types of ecological outfall (What rare earth elements will be mined to make these things?) and a hundred other things. But again, these kinds of questions already exist with in-person conferences (How much money can the organization afford for conference travel? Who gets it? What's the carbon footprint of an ALA Midwinter?). The fact that we can anticipate problems with virtual conferences shouldn't disqualify them as an alternative to face-to-face meetings. Rather, we should try to be honest about weighing the costs and benefits of both approaches fairly.

\section{McLure:}

Seriously, Karen, I'm supposed to come up with an argument on par with the potential of the Oculus Rift? Well, I will caution that we will have to expect at least hiccups with technology as we march forward, just as we have experienced to date. We're all too familiar with those moments when the sound quality is unbearable (or there's no sound at all) and it costs you half an hour of your virtual conferencing day. Admittedly, technology or our interactions with it can be troubled in the face-to-face setting, too (Weren't you once at a session where the laptop started smoking?), but those problems are usually easier to work around in person. A broken projector means the presenter does without his or her PowerPoint; a broken virtual reality device will mean ... no conference at all.

While we are certainly making progress with technology and its reliability, I would mention that effective, optimal presentation can look very different in the virtual setting than it does in person. Currently, it seems challenging for speakers to cater to both modes unless they actually deliver two distinct versions of the presentation. With time and technology this too may be resolved, but until then, it seems that the options are either asking presenters to double their workloads or asking some of the attendees to accept an inferior version of the experience.

However, I should concede that virtual conferences offer another, incredibly important improvement over the traditional approach: the potential for more diverse conference participants and presenters will increase dramatically when the costs of participation (financial costs, physical travel, time spent traveling, and more) are reduced or eliminated.

\section{Munro:}

I don't remember a smoking laptop, although I'm sure it's happened to some poor soul. And yes, you're right, the Oculus Rift is an outlier example at this point. But give us ten to twelve years...

Anyway, the elephant in the room that we haven't really acknowledged yet is COST. And I want to close with that, because it feels essential.

The future is never perfectly linear, so I won't claim certainty that the costs of air travel are going to go straight up from here on out. But right now I think we're subsidizing business travel in all kinds of ways, just as we subsidize other consumptive activities. There are these things called "externalities," which are costs that businesses like to ignore or pass along. Climate change is one big, relevant example.

We all know that air travel is ecologically costly_but we don't see that cost reflected in the price of airfares. You don't 


\section{TAKING ISSUES}

pay a carbon tax, for instance, on your plane ticket. That's not because there's no carbon cost to your flight; it's because we've chosen to ignore it. Airlines don't have to tally up their carbon footprints in their annual reports and pay anything based on the ozone depleted, or the petroleum consumed, or the water used. We just don't do business that way.

But-and I don't want to sound too apocalyptic here, but if you follow climate news, things are getting pretty real pretty fast-we may soon be forced to start reckoning with these hidden costs. I don't know exactly how that will play out, but as water and oil and energy become scarcer and costlier, as hundred-year storms start happening more often, as the cost of the in-flight meal goes up because food prices are fluctuating, as labor markets migrate and evolve, and so on, I think we may start to see those things reflected in the cost of travel. And I actually think that will be a good thing, if only in terms of our accountability.

I think sooner or later, we'll find our backs against the wall and we'll have to start paying more for things like business travel. And that, in turn, will force us to examine the idea a little more closely. Do we really want to pay $\$ 2,000$ for a flight to Chicago? Can we really afford it?

And most of all, is it worth it?

\section{McLure:}

I expect that the question "Can we afford and justify the cost of conferencing?" will continue to require close scrutiny by all. I don't doubt that sometimes the answer will be "no." All too often, it already is. Many librarians don't receive any employer-provided funding to attend conferences, and many librarians who previously received solid funding are now receiving less or none in these leaner economic times. So, it's important to recognize that those of us who've been lucky to receive continuing support are privileged.

Because I really value the participatory, collegial aspect of face-to-face conferences, I'm conflicted. I hope that we will confront these challenges head-on and find a way to salvage in-person conferencing. Sometimes tremendous creativity results from confronting constraints. I hope, optimistically, that we see more creative solutions and developments than we can yet imagine.

It seems that, if we were on the cusp of a significant shift to virtual conferencing as the preferred approach, we would see face-to-face conferences shrink or dwindle, wouldn't we? Yet the opposite is true, at least in my observation. It seems to me that in the years since we graduated, the range of faceto-face national and international conferences for academic librarians has only grown (and that's even putting aside the small feast of virtual and local professional development conference options available in many geographical locations).

I worry that the increasing range of virtual conference options will lead to fewer librarians receiving employer funding to attend face-to-face conferences. You might counter that this would not be entirely a bad thing, but I'd really like to see both options persist and for the choice to be left to individuals, wherever possible. And I would hate to think of new librarians, in particular, entering the profession in a new era of all-virtual/all-local—end of story—professional development.

I think my hope for the nearer future is that many employers will continue to see the value of face-to-face conferencing, and to support their librarians' attendance, but that with everexpanding and improving virtual conference options, and especially virtual professional service opportunities, librarians and organizations will feel some new ability to make different choices. If, as you suggest, our expectations and hopes for conferences keep changing, perhaps fewer librarians will need to attend conferences to fulfill service requirements or as their primary networking opportunity. My hope, in that case, would be that that development might free up resources for librarians to attend face-to-face conferences for essentially new reasons. For instance, as a liaison librarian, I've often felt that it would be so educational to attend conferences within the academic disciplines that I serve, but to do that regularly in the past would have meant choosing between library-related and disciplinary conferences.

More importantly, I think it's exciting that virtual service and conference options may increasingly make both activities available to librarians who've not been able to pursue either. That reality has always bothered both of us, and I think it's been a longstanding and widespread concern that's come up many times in discussions at conferences. That we might finally be able to inch past it is exciting, even if it's taken far too long to get here.

\section{Munro:}

Hear, hear. And I hope that however this all plays out, we still get to see each other (virtually or for real) in the library conference world of the future.

\section{Reference}

1. Association of College and Research Libraries, "ACRL History," accessed August 4, 2014, www.ala.org/acrl/aboutacrl/history/history. 